\title{
Nephropathy and Encephalopathy in an Indonesian Patient with Dengue Viral Infection
}

\author{
Dedi Rachmadi, Mohamad Yanuar Anggara
}

Department of Child Health, Faculty of Medicine, Universitas Padjadjaran-Dr. Hasan Sadikin General Hospital

\begin{tabular}{|c|c|}
\hline Abstract & $\begin{array}{l}\text { Objective: To describe unusual manifestation of dengue virus infection that has } \\
\text { been increasing in number and elucidate the indirect effect of dengue infection } \\
\text { on the central nervous system which may explain the occurence of dengue } \\
\text { encephalopathy. }\end{array}$ \\
\hline & $\begin{array}{l}\text { Methods: A case report of 6-year-old boy who was admitted with a history of } \\
\text { fever for three days, accompanied with decreased consciousness, hypertension, } \\
\text { and edema is presented. Laboratory examination showed hemoconcentration, } \\
\text { thrombocytopenia, with positive anti dengue Immunoglobulin G (IgG) and IgM, } \\
\text { microscopic glomerular hematuria, and proteinuria as well as normal creatinine } \\
\text { serum level. He was treated with supportive treatment. }\end{array}$ \\
\hline & $\begin{array}{l}\text { Results: After six days, the consciousness was improved and blood pressure was } \\
\text { normal. Proteinuia was alleviated by Day } 11 \text { and completely negative on Day } 19 . \\
\text { Microscopic glomerular hematuria was negative after } 6 \text { months. }\end{array}$ \\
\hline November 28, 2012 & Conclusions: Recognition of unusual dengue manifestations is important in early \\
\hline $\begin{array}{l}\text { Revised: } \\
\text { December 28, } 2012\end{array}$ & Keywords: Dengue virus infection, encephalopathy, nephropathy \\
\hline $\begin{array}{l}\text { Accepted: } \\
\text { February 1, } 2013\end{array}$ & IJIHS. 2013;1(1):49-52 \\
\hline
\end{tabular}

\section{Introduction}

Dengue virus infection can be classified clinically into dengue and severe dengue infections. It is a common arthropod-borne viral disease which is endemic in more than one hundred countries. This infection is caused by 4 serotypes of dengue virus; DEN-1, DEN-2, DEN-3, and DEN-4, an RNA flavivirus member within the flaviviridae family. Worldwide, more than 2.5 billion people are at risk and about 50-100 million dengue infection cases occur annually. ${ }^{1}$ In recent years, there have been increasing reports of unusual manifestation of dengue viral infection that includes manifestations in renal and central nervous systems. Renal involvement in several cases has been reported to be accompanied by acute kidney injury with or without shock, hemolyisis, rhabdomyolysis, as well as sepsis. In several cases, glomerular injury was shown to be mediated by the immune complex. ${ }^{2,3}$ Renal injury

\footnotetext{
Correspondence:

Dedi Rachmadi, Department of Child Health, Faculty of Medicine, Universitas Padjdajaran-Dr. Hasan Sadikin General Hospital

Jl. Pasteur No. 38, Bandung, Indonesia

e-mail: deddyrachmadi@yahoo.com
}

may manifest as increased creatinine excretion, proteinuria, glomerulonephritis, acute kidney injury and hemolytic uremic syndrome..$^{2,4,5}$ The indirect effect of dengue infection on the central nervous system may explain the occurrence of encephalopathy. The encephalopathy was considered to be secondary to vasculitis with resultant fluid extravasation, cerebral edema, hypoperfusion, hyponatremia. This condition is also accompanied by renal and hepatic failures. ${ }^{6}$ Other mechanisms involved have been attributed to microcapillary hemorrhage and release of toxic substances. ${ }^{7}$

\section{Case}

A 6-year-old boy was admitted to Dr. Hasan Sadikin General Hospital with a history of tonicclonic type seizure an hour prior to admission. The seizure lasted for 5 minutes after which the patients looked drowsy. There was a history of edema since 10 days prior to admission and fever for 6 days prior to edema. There was no history of rash, sore throat, skin infection, icteric, or photosensitivity. This was the first seizure 
occurrence and there was no history of seizure in the family. On physical examination, the patients seemed drowsy and confused (Glasgow coma scale/GCS=12), the blood pressure was $150 / 100 \mathrm{mmHg}$. There was edema observed in the palpebra, the pretibial and also the dorsum of pedis. Hepatosplenomegaly was also seen. Other physical and neurological examinations were unremarkable. Laboratory investigations showed hemoconcentration, thrombocytopenia, hypoalbuminemia $(1.9 \mathrm{~g} / \mathrm{dL})$ with a normal total protein level $(7.7 \mathrm{~g} / \mathrm{dL})$. Ureum and creatinine serum level were within normal limits $(17 \mathrm{mg} /$ $\mathrm{dL}$ and $0.17 \mathrm{mg} / \mathrm{dL}$ ). Liver function test and electrolyte serum level were also within normal limits. Urinalysis revealed +2 proteinuria and 6-8/ hpf positive hematuria. Serological examinations with anti-dengue IgG and IgM rapid test were positive, anti-streptolysin-O (ASTO), antibody antinuclear (ANA) and anti-double stranded DNA (anti-ds-DNA) were negative. C-reactive protein (CRP) and C3 protein levels were also within normal values. Lumbal puncture was normal and blood culture was negative. All laboratory investigations were performed at the Clinical Pathology Laboratory of Dr. Hasan Sadikin General Hospital, except for C3 protein examination which was performed at Prodia laboratory. For hematological examination, KX21 machine was used. ANA test was conducted by MicroELISA technique, anti-ds DNA was conducted by immunofluorescent technique, and dengue serology test was conducted using rapid technique with Pandio kit. Chest X-ray showed neither cardiomegaly or pulmonary edema. The patient was treated with Ringer lactate infusion $3 \mathrm{~mL} / \mathrm{kg}$ body weight/hr, intravenous furosemid 2x15 mg and oral captopril $2 \times 6.25 \mathrm{mg}$. During hospitalization, consciousness improved dramatically, no repeated seizure, and blood pressure was normalized on Day 11 . Urinalysis showed improvement of proteinuria. On Day 12 , the patient was discharged and was followed up in the out-patient clinic. During follow up, the clinical conditions improved and proteinuria was finally negative on Day 19. Microscopic glomerular hematuria were not found after 6 months.

\section{Discussion}

The pathogenic link between viral infections and concomitant renal dysfunction is often difficult to establish. The causal association may be suggested by the findings of specific viral antigen serology and host antibodies in the renal structures. Improvement of the renal disease accompanied by the clearance of viral antigen or recurrence of renal dysfunction following reinfection may offer the causal-effect link. ${ }^{8}$ The case presented here raises some issues related to the immunopathologic mechanisms in the course of dengue infection and its implication in renal injury.

The pathogenesis of dengue nephropathy may be the same to that in acute-post streptococcal glomerulonephritis, where an

Table 1 Laboratory Investigation Follow up of the Patient

\begin{tabular}{|c|c|c|c|c|c|c|c|}
\hline \multirow{2}{*}{$\begin{array}{l}\text { Laboratory } \\
\text { examination }\end{array}$} & \multicolumn{7}{|c|}{ Day of illness } \\
\hline & 6 & 7 & 11 & 19 & 28 & 68 & 185 \\
\hline Hematocrit (\%) & 40 & 33 & 30 & & & & \\
\hline Thrombocyte (x106/L) & 98 & 117 & 187 & & & & \\
\hline Ureum (mg/dL) & 17 & & & & & & \\
\hline Creatinine $(\mathrm{mg} / \mathrm{dL})$ & 0.17 & & & & & & \\
\hline Urine protein & ++ & ++ & + & negative & negative & negative & negative \\
\hline Erythrocyte urine (/hpf) & $6-8$ & $>10$ & $>10$ & $>10$ & $>10$ & 8 & negative \\
\hline Cholesterol (mg/dL) & 124 & & & & & & \\
\hline Albumin $(\mathrm{g} / \mathrm{dL})$ & 1.9 & & & & & & \\
\hline Protein (g/dL) & 7.7 & & & & & & \\
\hline IgG/IgM anti-dengue & & $+/+$ & & & & & \\
\hline ASTO & & negative & & & & & \\
\hline CRP (mg/L) & & 1.3 & & & & & \\
\hline
\end{tabular}


antigen-antibody complex was found in the glomerulus in several cases. Various mechanisms are involved in this pathogenesis which can be classified as a circulation mechanism or an insitu mechanism. In the circulation mechanism, the viral antigen would be deposited alone or as an antigen-antibody complex. The insitu immune mediated mechanisms involving viral antigens result in humoral and cellular responses, including the release of cytokines and chemokines. ${ }^{8}$ Appel underlined how the immune complex-induced glomerular injury occurs in viral disease. The glomerular injury was induced by the immune complex through various mechanisms including immune complex deposit circulation in the glomerular structures, mimicry effect, autoimmune reaction, activation of cytokines and adhesion molecules by virus, or direct cytopathic effect of viral proteins on glomerular and tubular cells. ${ }^{9}$ Included also in the pathogenesis are the host factors such as age, sex, genetic background, socio-economic status, and access to health services. In addition, there was a hypothesis that some viruses have a nephropathogenic characteristics.

There were 15 cases of nephropathy dengue that have been reported. ${ }^{8}$ Mostly, the dengue infection induced renal injury was accompanied by shock, rhabdomyolysis, and hypotension. In contrast to the previous reports on dengue infection induced renal injury, a case of dengue infection induced glomerulonephritis without shock, hypotension, or rhabdomyolyisis was reported..$^{10}$ In Thailand, some similar cases were also reported. Renal biopsy showed mesangial and endotel hypertrophy and hyperplasia, presence of monocyte-like cells in some of the glomerular capillary lumen, and focal thickening of the glomerular basement membrane. Immune complexes (IgG, IgM or both and C3) were found at glomeruli and arterioles wall. ${ }^{2}$ In this patient there was neither sign of shock or acute renal failure but there were signs of acute nephritic syndrome with IgG antigenemia and IgM anti dengue without elevated ASTO level. Renal biopsy was not conducted.

Microscpoic hematuria is a common finding in nephropathy. Hematuria is defined as the presence of red blood cells more than five per high power field in the urine in more than two occasions. ${ }^{9,10}$ Microscopic abnormalities including hematuria and proteinuria may persist for months to a year and, rarely, even longer but it will show marked improvement on nephropathy..$^{10}$ In the present case, on Day 19 proteinuria disappeared and microscopic hematuria disappeared after 6 months.

Encephalopathy dengue was thought to be secondary to vasculitis with resultant fluid extravasation, cerebral edema, hypoperfusion, hyponatremia, hepatic and renal failure, frank hemorrhage or microvascular or encephalitis from dengue virus infection. ${ }^{11}$ In this patient, there was decreased level of consciousness without CSF abnormality. In conclusion, we have presented a case of dengue encephalopathy with nephropathy without any evidence of acute renal failure, shock, hypovolemia, or sepsis. We attributed nephropathy to dengue infection following positive IgG and IgM anti dengue and after exccluding all other possible causes. We proposed a notion that nephropathy occurrence in dengue is an immune complex mediated phenomenon.

\section{References}

1. World Health Organization. Dengue guideline for diagnosis, treatment, prevention, and control. Geneve: WHO Press; 2009.

2. Nair VR, Unnikrishnan D, Satish B, Sahadulla MI. Case report acute renal failure in dengue fever in the absence of bleeding manifestations or shock. Infect Dis in Clin Pract. 2005;13:142-3.

3. Karakus A, Banga N, Voorn GP, Meinders AJ. Dengue shock syndrome and rhabdomyolisis. Neth J Med. 2007;65(2):78-81.

4. Uphadaya BK, Sharma A, Khaira A, Dinda AK, Agrawal SK, Triwari SC. Transient IgA nephropathy with acute kidney injury in a patient with dengue fever. Saudi J Kidney Dis Transpl.
2010;21(3):521-5.

5. Lima QE, Gorayeb FS, Zanon JR, Nogueira ML, Ramalho HJ, Burdmann EA. Dengue haemorrhagic fever-induced acute kidney injury without hypotension, haemolysis or rhabdomyolysis. Nephrol Dial Transplant. 2007;22(11):3322-6.

6. Witayathawornwong P. Fatal dengue encephalitis. Southeast Asian J Trop Med Public Health. 2005;36(1):201-2.

7. Cam BV, Fonsmark L, Hue NB, Phuong NT, Poulsen A, Heegard ED. Prospective case control study of encephalopathy in children with dengue hemorrhagic fever. Am J Trop Med Hyg. 2001;65(6):848-51. 
8. Kimmel PL, Moore Jr. Viral glomerulonephritis. In: Schrier RW, editor. Disease of the kidney and urinary tract. $8^{\text {th }}$ ed. Philadelphia: Lipincott Williams and Wilkins; 2007. p. 1478-80.

9. Appel G. Viral infections and the kidney. Cleve Clin J Med. 2007;74(5):353-60.

10. Feld LG, Meyers KEC, Kaplan BS, Stapleton FB.
Limited evaluation of microscopic hematuria in pediatrics. Pediatrics. 1998;102(4):1-5.

11. Chotmongkol V, Sawanyawisuth K. Case report dengue hemorrhagic fever with encephalopathy in an adult. Am J Trop Med Hyg. 2004;35(1):1603. 